\title{
Retaining Diverse Students in Civil Engineering and its Subdisciplines: Chal- lenges and Opportunities
}

Dr. Abbie B Liel P.E., University of Colorado, Boulder

Dr. Abbie B. Liel is an associate professor of Civil, Environmental and Architectural Engineering at the University of Colorado Boulder.

\section{Eva Leong}

Ms. Eva Leong is a Staff Engineer at Big R Bridge. She earned her M.S. degree in civil engineering at University of Colorado Boulder in 2012. 


\section{Retaining Diverse Students in Civil Engineering and Its Subdisciplines: Challenges and Opportunities}

\section{Introduction}

There are many benefits to a diverse workforce of civil engineers. In particular, work-place innovation, creativity, knowledge and productivity have been shown to be enhanced when many perspectives and experiences are represented. ${ }^{1}$ As the civil engineering profession tackles some of big challenges facing society in the $21^{\text {st }}$ century, it is critical that we are able to recruit and retain the most talented students, regardless of gender or race/ethnic background. Unfortunately, engineering schools continue to be challenged by student retention, and, for example, only about $70 \%$ of entering engineering freshman at our large public university graduate with an engineering degree within six years. Although retention is a challenge for all students, it is particularly apparent for women and minority students whose representation in engineering decreases at every education and career milestone. ${ }^{1,2}$ As a result, women and minorities still make up a small fraction of those earning engineering degrees. At our institution, a public university in the state of Colorado, the undergraduate population is about $20 \%$ women and $8 \%$ underrepresented minorities (compared to $20 \%$ and $11 \%$ nationally). Moreover, only about $15 \%$ of practicing civil engineers in some subdisciplines, like structural engineering, are women. ${ }^{3}$ In contrast, women now make up over $30 \%$ of lawyers and physicians, and over $70 \%$ of psychologists. Since no evidence exists that significant gender or racial differences in math or science ability exist ${ }^{1,4}$, discrepancies in persistence, engagement and achievement in engineering have been attributed to a range of factors including a lack of preparation ${ }^{5}$ and encouragement ${ }^{6}$, workplace $^{7,8,9}$ and academic ${ }^{10}$ environments, and the public image of engineering ${ }^{11}$. Yet, little research has examined why some engineering fields are more successful at recruiting and retaining a diverse student body and workforce than others and what factors affect individual's choice of a discipline or subdiscipline of engineering. In addition, it remains unclear to what extent patterns observed of diversity in engineering as a whole are representative of specific disciplines.

To improve our understanding of the factors that influence the persistence of various groups of students in civil engineering education and careers, this paper describes findings from a survey taken by 223 undergraduate (165) and graduate students (58) in civil engineering. The survey aims to address the following questions:

- What are the factors that affect why women and minorities choose to pursue education in civil engineering?

- What aspects of the civil engineering curriculum and course work do students find particularly motivating and interesting? Do students feel that they have a mentor? What kind of work experience and internships have students had? Are they members of student/professional engineering organizations? Do the answers to this question depend on the gender or ethnic/racial background of the student?

- How do students perceive civil and structural engineering careers and their own opportunities for success in this profession? Are these perceptions different for women and minority students?

We explore both civil engineering and the subdiscipline of structural engineering because structural engineering has historically been one of the least diverse areas within the broader field 
of civil engineering. Reasons for the lack of diversity in structural engineering, and challenges related to retention and recruitment of a diverse workforce in that particular area of civil engineering, have never been examined. This study focuses especially on women, and African Americans, Native Americans and Hispanics, following the typical designation of these groups as "underrepresented minorities" (URM) in engineering.

\section{Current state of diversity of U.S. universities' civil engineering programs}

To begin, we quantify the current state of diversity of U.S. universities' civil engineering programs. Specifically, the study examines the demographics of students and faculty at the top civil engineering programs in the U.S. (as listed in the US News \& World Report 2012 ranking). Data quantifying the representation of women and underrepresented minorities among university faculty, graduate, and undergraduate students were collected from civil engineering departments. Where possible, specific information about structural engineering faculty and students was recorded separately.

The data were collected primarily by emailing department chairs, administrative staff or faculty at the top 50 universities listed in the US News \& World Report 2012 ranking. Of the emails sent, 28 responses were received, although not all responses contained complete information. When universities did not respond or responded with missing data, the remaining information was collected from the American Society for Engineering Education (ASEE) database. ${ }^{12}$ This database records the number of engineering faculty and students enrolled in ABET-accredited universities and separates the faculty and students based on gender and ethnicity. Since the ASEE data are aggregated by department, ASEE does not have information regarding students and faculty specifically with emphasis in structural engineering. Data for each university includes the total number of civil engineering students and faculty, and the number in each gender or race/ethnic group, and these values are used to determine the gender and racial breakdown nationally, with the results provided in Table 1.

Table 1 shows that there are fewer women than men among all cohorts (undergraduate students, graduate students, and faculty) and even fewer underrepresented minorities. The percentage of African Americans in less than 3\%, and the representation of Native Americans is near zero. However, there is significant variation in gender and racial diversity among the universities, as indicated in the rows labeled "max" and "min" in Table 1. For example, one university has an undergraduate civil engineering population that is $59 \%$ women; another school's undergraduate population is $15 \%$ Hispanic. Although the data for structural engineering specifically is more limited and the trends are less clear, Table 1 seems to reveal somewhat higher percentages of women and minority students in civil engineering, as compared to the structural subdiscipline. Table 1 also shows that undergraduate students typically include a higher percentage of women and minorities compared to the graduate students, which are in turn generally greater than that observed among faculty. The differences between undergraduate and graduate students likely indicate variable patterns of attrition from the field among different groups of students. An alternative hypothesis is that there are more women and minorities starting civil or structural engineering studies now than there were in the past, so the graduate student diversity will increase as these students continue through the pipeline. However, nationwide data shows that, if anything, women and minority representation among students in science and engineering 
disciplines has decreased slightly over the past 10 years ${ }^{2,5}$, making this hypothesis unlikely.

Table 1. Demographic data obtained for university students and faculty in civil (C) and/or structural (S) engineering.

\begin{tabular}{|c|c|c|c|c|c|c|}
\hline & \multicolumn{2}{|c|}{ FACULTY } & \multicolumn{2}{|c|}{$\begin{array}{l}\text { UNDERGRADUATE } \\
\text { STUDENTS }\end{array}$} & \multicolumn{2}{|c|}{$\begin{array}{l}\text { GRADUATE } \\
\text { STUDENTS }\end{array}$} \\
\hline & $\mathbf{C}$ & $\mathbf{S}$ & $\mathbf{C}$ & $\mathbf{S}$ & $\mathbf{C}$ & $\mathbf{S}$ \\
\hline & \multicolumn{6}{|c|}{ Number of Universities for which Data is Obtained } \\
\hline & 48 & 14 & 49 & 4 & 49 & 10 \\
\hline \multicolumn{7}{|c|}{ Gender } \\
\hline \% Women & 17.4 & 18.7 & 24.8 & 24.3 & 29.2 & 20.5 \\
\hline (Max) & 31.8 & 45.5 & 59.2 & 28.9 & 44.6 & 36.1 \\
\hline (Min) & 0.0 & 0.0 & 13.4 & 13.5 & 16.4 & 4.8 \\
\hline$\%$ Men & 82.6 & 81.3 & 75.2 & $\mathbf{7 5 . 7}$ & 70.8 & 79.5 \\
\hline \multicolumn{7}{|c|}{ Race/Ethnic Background } \\
\hline $\begin{array}{l}\% \text { African } \\
\text { American }\end{array}$ & 1.1 & 1.5 & 2.9 & 1.8 & 2.0 & 1.2 \\
\hline$\%$ Hispanic & 6.1 & 2.2 & 10.3 & 14.9 & 4.3 & 2.9 \\
\hline $\begin{array}{l}\% \text { Native } \\
\text { American }\end{array}$ & 0.0 & 0.0 & 0.6 & 0.7 & 0.2 & 0.2 \\
\hline$\%$ URM & 7.2 & 3.7 & 13.9 & 17.5 & 6.5 & 4.2 \\
\hline (Max) & 22.2 & 66.7 & 77.4 & 26.3 & 35.6 & 13.3 \\
\hline (Min) & 0.0 & 0.0 & 2.5 & 5.4 & 1.6 & 0.0 \\
\hline $\begin{array}{l}\% \text { White and } \\
\text { Others }{ }^{\#}\end{array}$ & 92.8 & 96.3 & 86.1 & 82.5 & 93.5 & 95.8 \\
\hline
\end{tabular}

\section{Survey design and dissemination}

The survey described in this paper was distributed to both undergraduate and graduate students. We recruited participants studying civil or architectural engineering at U.S. universities. The survey targeted students with at least junior standing, to ensure that they had substantial engineering-related course experiences. At the graduate level, we targeted solely students pursuing degrees in the area of structural engineering.

The web-based survey was designed according to best practices in survey design, in terms of visual arrangement, types, and organization of questions and compatibility with multiple web browsers $^{13}$, and implemented on the Google Forms platform. The primary topics covered in the survey are summarized in Table 2, with a focus on exploring factors that previous research have demonstrated affect retention, persistence and diversity ${ }^{5-10}$. To test the clarity and the length of the survey, the survey design was distributed to a small number of pre-identified respondents for feedback, and the survey questions updated before broader dissemination. A link to the survey was disseminated through email and other electronic media via students, faculty, and staff at universities with major civil engineering programs. Faculty and staff at a number of universities were asked to forward the survey to student email distribution lists. Social media platforms, including Facebook and LinkedIn, were also used to reach a wider number of potential respondents. The survey was live in October and November, 2012. The survey design and recruitment methods were reviewed and approved by the university IRB office before distribution. 
We are unable to quantify the response rate because we do not know how many individuals received the link, but response rates for web-based surveys with a significant number of questions tend to be relatively low. ${ }^{6}$ Participants responses were excluded from the analysis if any of the following conditions occurred: (1) if the respondent did not provide information about his/her gender; (2) if the respondent did not finish the survey; or (3) if the respondent took the survey more than once. Early respondents were offered a $\$ 5$ Starbucks gift card for participating.

\begin{tabular}{|c|c|c|}
\hline Part & Description & $\begin{array}{l}\text { \# of } \\
\text { Questions }\end{array}$ \\
\hline 1 & $\begin{array}{l}\text { Demographics (gender, race/ethnic background, age, etc.), family } \\
\text { background, and basic information about current educational activities }\end{array}$ & 13 \\
\hline $2 \mathrm{a}$ & $\begin{array}{l}\text { Undergraduate students only: Experiences during their civil, architectural, } \\
\text { or structural engineering education; memberships in student organizations, } \\
\text { and future plans }\end{array}$ & 45 \\
\hline $2 b$ & $\begin{array}{l}\text { Graduate students only: Experiences during their structural engineering } \\
\text { education; memberships in students and/or professional organizations, and } \\
\text { future plans }\end{array}$ & 49 \\
\hline 3 & $\begin{array}{l}\text { Traits of successful engineers, opportunities and challenges that people of } \\
\text { different backgrounds face in engineering; }\end{array}$ & 4 \\
\hline 4 & Feedback on the survey & 4 \\
\hline
\end{tabular}

\section{Demographics and background of survey respondents}

In total, 223 responses are included in the final analysis. Of these, 165 are undergraduate students and 58 are graduate students. As shown in Table 3, 51\% of the undergraduate respondents are men, compared to $67 \%$ of the graduate student respondents. Among both groups, the majority of the respondents are white; the survey received responses from very few African Americans and no individuals identifying as Native American. The graduate student population appears to have somewhat more race/ethnic diversity. On average the undergraduate respondents were 19-20 years old, and the graduate respondents were 23-24 years old. The survey did not distinguish between American and international students, who answered questions about race/ethnicity with the same options as other students.

\section{$\underline{\text { Undergraduate Student Respondents }}$}

The undergraduate students were largely juniors $(38 \%)$, seniors $(45 \%)$ and $5^{\text {th }}$-year seniors $(17 \%)$. Most of the respondents attended large public universities $(62 \%)$, with other responses coming from students at large private universities, small private universities, and small public universities. We received no responses from students attending liberal arts or community colleges.

Although the survey reached out to all undergraduates in civil or architectural engineering, the survey did inquire about student's primary disciplinary interest or area of emphasis. For men, respondents reported pursuing subdisciplines of structures (34\%), construction management $(16 \%)$, and architectural design (10\%). For women, the top three disciplines reported were: structures $(29 \%)$, environmental (14\%), and construction management (12\%). These 
distributions are likely not representative of the undergraduate civil engineering population, as we intended to reach more students interested in structural engineering than other subdisciplines through our survey participation recruitment strategy. In total, $89 \%$ of the undergraduate respondents said they had considered choosing in structural engineering at some point during their higher education.

Table 3. Gender and race/ethnic background of student survey respondents.

\begin{tabular}{lcc} 
& Undergraduate & Graduate \\
\hline Men & Gender \\
Women & $50.9 \%$ & $67.3 \%$ \\
\hline \multicolumn{3}{c}{ Race/Ethnic Background } \\
\hline White & $75.2 \%$ & $32.8 \%$ \\
Asian American or Pacific Islander & $7.9 \%$ & $56.9 \%$ \\
American Indian or Alaskan Native & $0.0 \%$ & $29.3 \%$ \\
Hispanic/ Latin American & $13.3 \%$ & $0.0 \%$ \\
Black/ African American & $1.8 \%$ & $10.3 \%$ \\
Other & $3.0 \%$ & $1.7 \%$ \\
\hline
\end{tabular}

\section{Graduate Student Respondents}

The survey reached 58 graduate students studying structural engineering. Sixty-percent of the students were pursuing an M.S. degree, with the other $40 \%$ pursuing a Ph.D. In addition, 47\% were in their first year of study at the time of the survey, $28 \%$ had been in graduate school for 1 2 years, and the remaining $26 \%$ had been in graduate school for at least three years. As with the undergraduate respondents, the bulk of the graduate respondents reported attending large public universities.

\section{Pre-university experiences: Why choose civil and/or structural engineering?}

The survey first asked both undergraduate and graduate students to identify when they decided to pursue education in civil, or structural, engineering as well as the factors that led then to pursue this area of study. Among undergraduate students, the majority (68\%) of respondents reported deciding to pursue civil engineering before the start of their junior years in college. Among graduate students, the majority $(60 \%)$ of respondents responded that they had decided to pursue civil engineering during high school; an additional $21 \%$ made this decision during the first few years of college. The survey also asked graduate students about when they decided specifically on structural engineering. In general, this decision was somewhat later than the decision to study civil engineering, typically in the middle to latter part of their undergraduate studies.

Responses to questions about the factors that led to this choice of discipline are provided in Table 4. The primary factors identified were interests in math and science, as well as because the practicality of engineering. These were mostly the same ${ }^{a}$ for the different subgroups of

\footnotetext{
${ }^{a}$ This paper emphasizes qualitative comparisons to describe survey results. However, differences between subgroups of respondents are only discussed in the text if the they are significant at the $10 \%$ level in a t-test. Where this significance is not present, differences are described in the text as being "small" or "negligible".
} 
respondents, although underrepresented minorities chose "desire to make a difference" at a higher rate than other groups, making it a more popular choice for this subset of respondents than either "interest in science" or "engineering is practical". The secondary factors identified (underlined in Table 4) also showed that women were more likely to mention the importance of making a difference. Men were more likely to cite the importance of a teacher/mentor encouragement, while women were more likely to point to a family member or close friend who is an engineer. URM students were less likely to mention a family member/friend who was an engineer, and more likely to report the influence of a teacher or mentor on this choice.

\section{University experiences: Undergraduate students}

\section{$\underline{\text { Courses and Skill Development }}$}

To explore students' university studies, the survey first asked questions about undergraduate students' experience with various required and optional courses, in order to explore how students of different gender and race/ethnic background experienced these courses. In one question, we asked students to identify the courses that they liked the most and the least, with the results illustrated in Figure 1. Among our survey group, structural analysis, structural design, statics, and fluid mechanics tended to be popular, whereas thermodynamics, statistics, and economics were less popular. (However, this result should be interpreted lightly as our survey reached more structures-oriented students.) The primary reasons given for liking or disliking a course related to the professor, and the professor's teaching style or method of presenting material, as well as the the students personal interest in the subject matter and material. There are no differences in the reasons given for liking or disliking a course between men, women, and minorities.

Table 4. What factor(s) led you to pursue studies in civil, architectural or structural engineering? Italics indicates the top three factors identified. Underline indicates the factors of secondary importance.

\begin{tabular}{|c|c|c|c|c|c|}
\hline Factor *† & Men & Women & Whites & URM & Others\# \\
\hline $\begin{array}{l}\text { Family member or close friend } \\
\text { was/is an engineer }\end{array}$ & $5.8 \%$ & $7.9 \%$ & $7.8 \%$ & $4.5 \%$ & $3.4 \%$ \\
\hline Teacher/ mentor encouragement & $6.7 \%$ & $5.3 \%$ & $5.5 \%$ & $9.8 \%$ & $1.8 \%$ \\
\hline Interest in math & $20.1 \%$ & $21.1 \%$ & $21.0 \%$ & $22.3 \%$ & $17.5 \%$ \\
\hline Interest in science & $15.6 \%$ & $13.9 \%$ & $14.7 \%$ & $14.3 \%$ & $14.0 \%$ \\
\hline Engineering is practical & $15.2 \%$ & $13.7 \%$ & $14.0 \%$ & $8.9 \%$ & $22.8 \%$ \\
\hline Job/ internship experiences & $4.5 \%$ & $2.9 \%$ & $4.2 \%$ & $1.8 \%$ & $3.5 \%$ \\
\hline $\begin{array}{l}\text { Past opportunities, activities, } \\
\text { summer camps }\end{array}$ & $1.3 \%$ & $2.9 \%$ & $2.2 \%$ & $2.7 \%$ & $1.8 \%$ \\
\hline Desire to make a difference & $11.2 \%$ & $12.4 \%$ & $10.5 \%$ & $15.2 \%$ & $14.0 \%$ \\
\hline $\begin{array}{l}\text { Wanted to get a degree that would } \\
\text { provide a solid foundation for } \\
\text { another career or field }\end{array}$ & $6.3 \%$ & $5.0 \%$ & $5.3 \%$ & $8.0 \%$ & $5.3 \%$ \\
\hline $\begin{array}{l}\text { Looking for a good compensation } \\
\text { and stability in my career }\end{array}$ & $9.8 \%$ & $12.1 \%$ & $11.5 \%$ & $10.7 \%$ & $12.3 \%$ \\
\hline Others/Not Sure etc. & $3.6 \%$ & $2.9 \%$ & $3.3 \%$ & $1.8 \%$ & $35 \%$ \\
\hline
\end{tabular}

*In this question, respondents were asked to identify the three most important factors from the list provided.

${ }^{\dagger}$ There were not significant differences in the responses between undergraduate and graduate students so both groups are combined in the data presented in this table.

\#Others includes non-white students who are not classified as underrepresented. 
Next, we asked the students to rate their experience with (a) structural engineering courses, (b) common science and math prerequisite courses, and (c) humanities and other elective courses, in terms of how much value these courses added to their engineering education and future career goals. Eighty-one percent of students reported having good or great experience with structural engineering courses (corresponding to to a survey selection of "some or significant value added to their engineering education"). This response was consistent across men and women and white and minority groups, and evidenced by comments like, "I really enjoy structural engineering. It's very tough, but rewarding nonetheless". Despite this generally positive response, $6 \%$ of respondents reported a poor or very bad experience that contributed to them losing interest in structural engineering. These responses were accompanied by comments like: "I feel many civil engineering students have been intimidated and disenchanted with structural engineering."

Somewhat fewer, $55 \%$, of student respondents had good or great experience with math and science prerequisite courses, and there were not substantial differences in the answers to this question based on gender or race/ethnicity. With regard to humanities and elective courses, 33\% said they had a good or great experience; again results were similar across subgroups of respondents. On average, students had taken about six elective (non-engineering) courses at the time of the survey. In addition, $28 \%$ of the respondents reported that they were pursuing another degree (either double major or minor) in addition to their engineering studies. Of these, students mostly commonly reported a degree in mathematics or statistics, with the second most students reporting a degree in business. There were several students pursuing additional degrees in either architecture or Spanish.

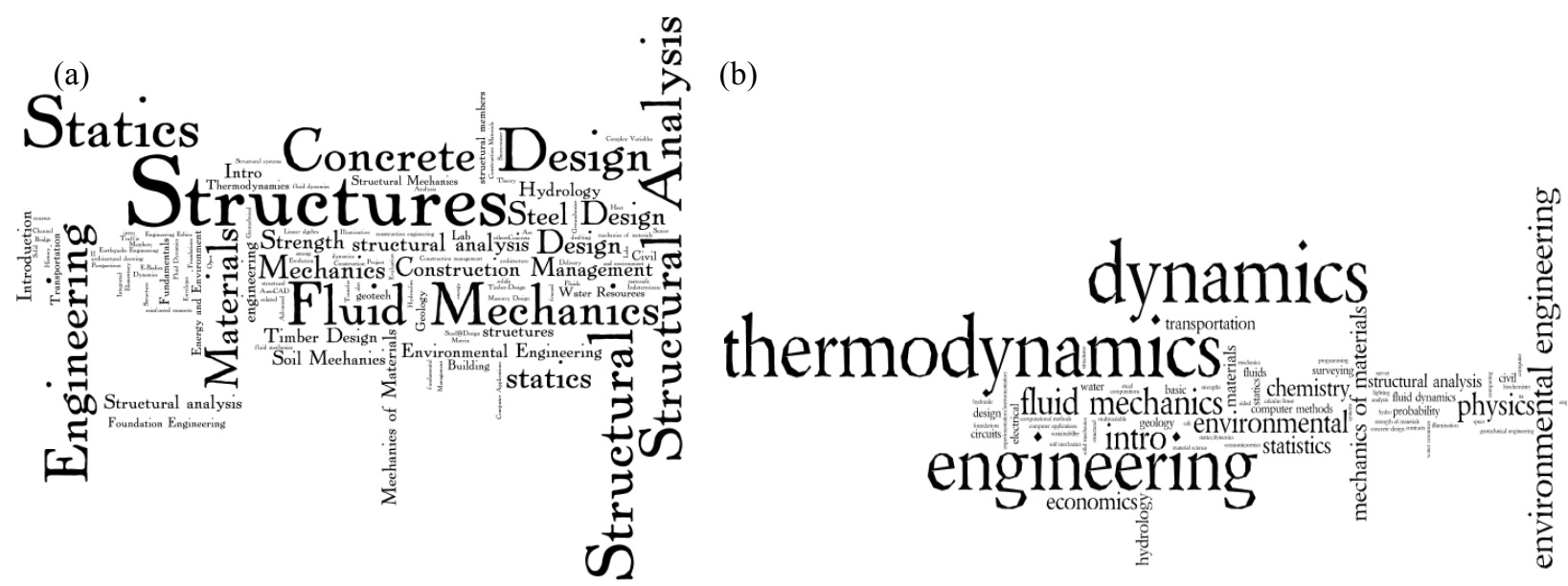

Figure 1. Word cloud showing responses to: (a) What engineering class have you enjoyed the most? and (b) What engineering class have you enjoyed the least? The size of the word indicates how often it appeared in the responses.

Respondents were then asked to identify the aspects of their engineering program that had most helped them succeed in engineering. The responses are summarized in Figure 2. Students responded that completing homework/assignments, and collaboration with fellow classmates, were most critical to their success (selected by $25 \%$ and $23 \%$ of students, respectively). Internship experiences were generally ranked lower than the other factors, but this may be because many students had not had an internship experiences at the time of the survey. Figure 2 also indicates men were more likely than women to point to their own technical skills and work ethic as being important (13\% vs. $7 \%$ ). On the other hand, slightly more women than men said 
that their study groups, textbook and handouts, lectures and activities in class, as well as engagement with the professor/teaching assistants, were important, but the differences are small. Compared to white men, underrepresented minorities' responses followed similar trends to those from women, putting less importance on technical skills, and more on engagement with classmates and professors and teaching assistants.

In addition to these multiple choice questions, in the open-ended questions at the end of the survey, a number of respondents chose to comment on the important role that faculty play in either encouraging or discouraging students from study in civil or structural engineering:

- "I think professors make the biggest difference in the experience a student has and the field of Engineering they pursue."

- "I almost dropped out of civil engineering due to horrible professors for basic classes (chemistry, physics, etc.) that aren't even associated with the engineering school. My engineering professors have been great."

- "I was initially interested in structural engineering but was turned off by the professor. His teaching style was terrible. He would just rush through all the topics and do long problems on the board and no one ever stopped to ask questions because he would make no effort to help us understand the topics."

These comments demonstrate the crucial role of professors as ambassadors of the profession in students' early careers.

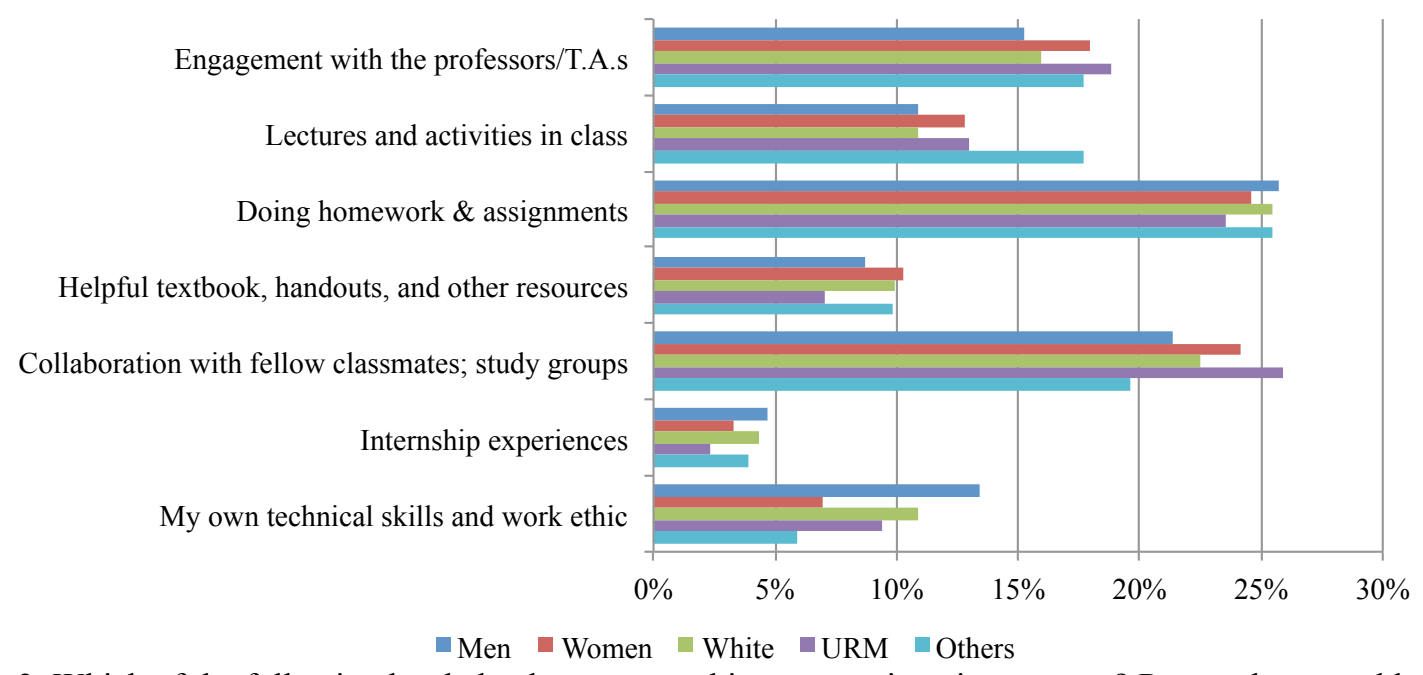

Figure 2. Which of the following has helped you succeed in your engineering courses? Respondents could select up to three choices.

The next section of the survey listed a number of different skills that are important for engineers, including both technical and non-technical skills. Students were asked to rate each skill on a scale of 1 to 5 according to how much they have improved these skills during their engineering education, where 1 signifies "I've improved these skills very little" and 5 signifies "I've improved these skills significantly". b As evidenced by results summarized in Table 5, the biggest improvements in skills were reported in critical thinking, engineering design and applications, and mathematics. Women reported somewhat higher improvements in written communication, oral communication, and leadership than men. There are some differences in the skills reported by underrepresented minorities and other minority groups (e.g., other minorities

\footnotetext{
${ }^{b}$ Note that the survey did not ask about how strong students felt their skills were at the beginning or end of their studies, instead asking them to assess their level of improvement.
} 
reported slightly higher gains in written and oral communication skills), but these differences are not significant due to the small sample sizes of survey respondents in these groups.

The survey also asked students for their perception of the difficulty of their engineering courses and their confidence in their technical skills. Responses about the difficulty level of the coursework (Figure 3) show that the largest number students reported that some engineering courses have been easy while other courses have been more difficult. However, women were more likely to say that courses were difficult or were becoming difficult, while men were more likely to say the difficultly was about right or that courses were becoming easier. In response to questions about confidence (Figure 4), students revealed that both men and women are fairly confident about their technical skills, or say that their confidence has increased as student. However, male respondents were more likely than female respondents to say that they were very confident, and less likely to choose options that expressed a lack of confidence.

Table 5. Respondents' ratings of skills developed during undergraduate education. Ratings were provided on a scale of 1 to 5. Italics indicates skills in which women reported higher improvements than men.

\begin{tabular}{|c|c|c|c|c|c|}
\hline Skills & Men & Women & White & URM & Others \\
\hline Written Communication & 3.0 & 3.2 & 2.9 & 3.4 & 3.8 \\
\hline Oral Communication & 3.0 & 3.1 & 3.0 & 3.2 & 3.8 \\
\hline Critical Thinking & 4.1 & 4.0 & 4.0 & 4.2 & 4.3 \\
\hline Leadership & 3.5 & 3.7 & 3.4 & 3.8 & 3.6 \\
\hline Ethics & 3.4 & 3.5 & 3.4 & 3.6 & 3.4 \\
\hline Mathematics & 4.1 & 3.9 & 4.0 & 4.3 & 4.2 \\
\hline Engineering design and applications & 4.1 & 4.1 & 4.1 & 4.2 & 3.9 \\
\hline $\begin{array}{l}\text { Information technology, } \\
\text { programming \& computer skills }\end{array}$ & 3.6 & 3.5 & 3.5 & 3.5 & 3.8 \\
\hline \multicolumn{6}{|c|}{ Courses have been easy } \\
\hline \multicolumn{6}{|c|}{$\begin{array}{c}\text { Some courses have been easy while other courses } \\
\text { have been more difficult }\end{array}$} \\
\hline \multicolumn{6}{|c|}{$\begin{array}{c}\text { The difficulty level of the courses has been about } \\
\text { right }\end{array}$} \\
\hline \multicolumn{6}{|c|}{$\begin{array}{l}\text { Courses were easy at first but are now becoming } \\
\text { more difficult }\end{array}$} \\
\hline \multicolumn{6}{|c|}{$\begin{array}{l}\text { Courses were difficult at first but are now becoming } \\
\text { easier }\end{array}$} \\
\hline \multicolumn{6}{|c|}{ Courses have been difficult } \\
\hline & 0 & $10 \%$ & $30 \%$ & $40 \%$ & \\
\hline
\end{tabular}

Figure 3. How would you describe the difficulty of the engineering courses you have taken?

To provide some additional context in this arena, the survey asked students to report their GPAs, with the distribution shown in Figure 5. These GPAs were very similar across respondents by gender and race/ethnicity: the average GPA for male students was 3.2, for women was 3.2, for white students was 3.3, and for minority students (URM and other) was 3.1. The statistics also reveal a somewhat higher standard deviation in men's grades than women's grades. Despite the similarities in GPA, though, men were much more likely to report their academic work is "above 
average" or "slightly above average" (65\% compared to $44 \%$ of women). Other minorities were less likely to report that their academic work was above average (44\% of respondents).

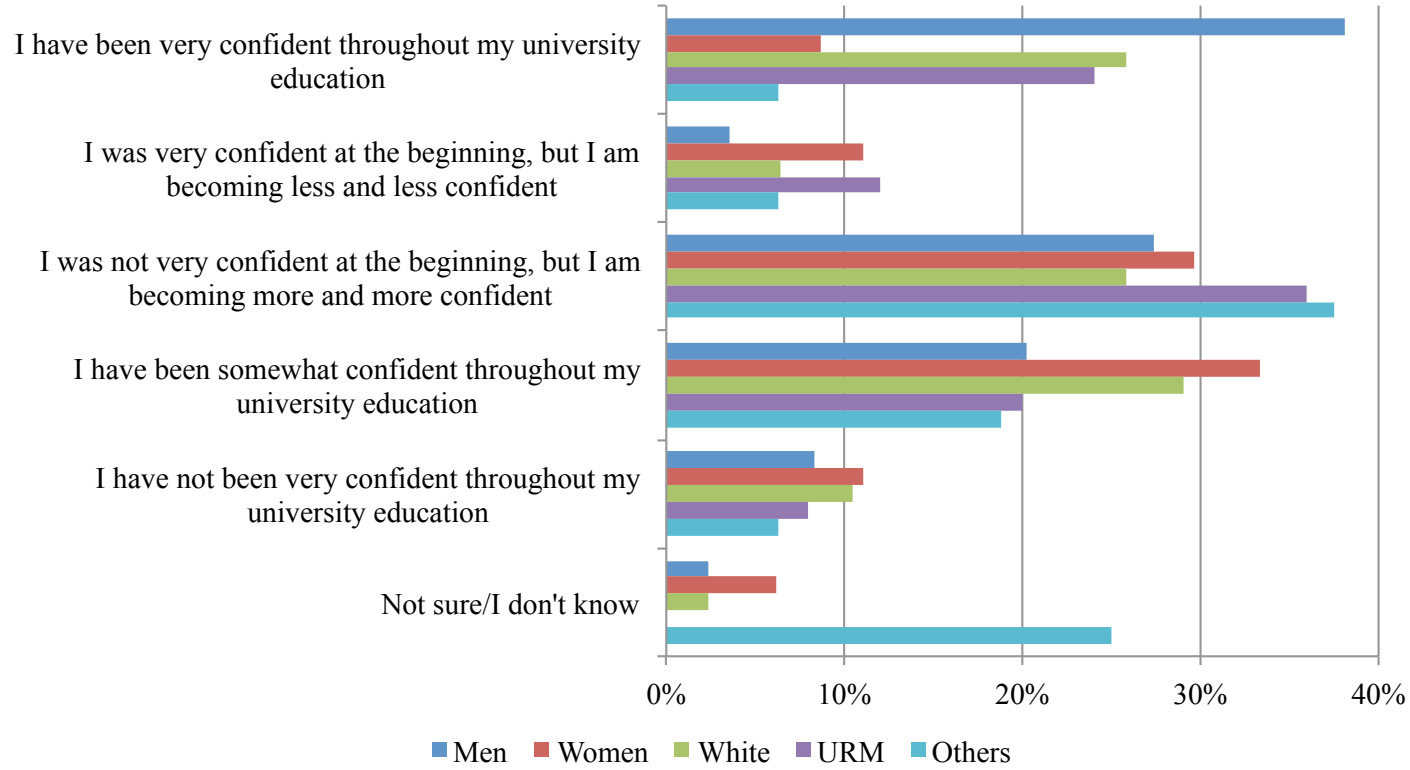

Figure 4. How confident do you feel about your technical abilities?

\section{$\underline{\text { Mentoring }}$}

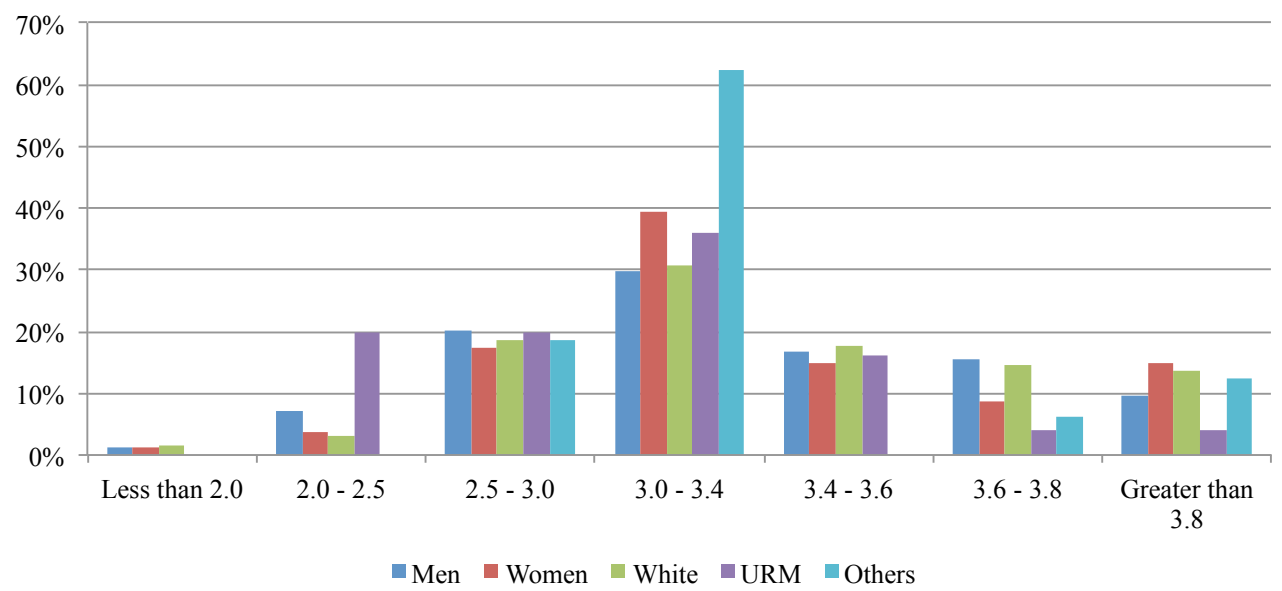

Figure 5. GPA self-reported by undergraduate students.

Most of the students $(66 \%)$ reported that they had a mentor that has strongly influenced education and career-related choices. Approximately half of the time, students reported that these mentors were a family member or relative. About $30 \%$ of the time, they cited a teacher or professor as an influential mentor.

\section{$\underline{\text { Retention }}$}

The survey reached only students currently studying civil, architectural, or structural engineering, not those who had left these degrees. However, a question on the survey did ask students whether they had ever considered switching majors. Fifty-three percent of the students 
answered "yes". Of these, $47 \%$ said they had considered switching to a non-engineering field, $25 \%$ said they had considered switching to another engineering discipline, and $28 \%$ reported that they started in another field and switched into civil engineering.

\section{Research, Internships and Work Experiences}

We also asked students to describe if their university offered any independent studies or research opportunities, and to report if they had participated in any internships during their education. The level of research and work experiences reported is very similar between men and women and between white and minority students, so the following summarizes the experiences reported by the undergraduate students as a whole. Seventy-four percent of the students said that they have not had any independent study or research activities with a professor at the time of the survey. However, $55 \%$ of the students had participated in internships. Of the students who had had internships, $18 \%$ have interned in a structural engineering office, $62 \%$ interned in a civil engineering office, and $18 \%$ interned in a non-engineering office. Students who have had internships reported that the experience made them more excited about a career in civil engineering. The majority of the students who had not had any internship experiences were interested in arranging an internship in the future.

\section{$\underline{\text { Involvement in Engineering Professional and Other Organizations }}$}

Ninety-four percent of the respondents reported that they were involved in an engineering society or professional group. The most common organization was American Society of Civil Engineers (47\% of respondents), followed by the Society of Women Engineers (14\% of respondents), and Engineers without Borders (12\% of respondents). Twenty-five of female engineers reported some involvement with SWE. Among underrepresented minorities, 21\% reported an affiliation with the Society of Hispanic Engineers. In addition, women and underrepresented minorities described a higher level of involvement with all of the organizations. For example, $17 \%$ of men reported involvement at the leadership level in one or more of these organizations, compared to $26 \%$ of women and $32 \%$ of underrepresented minority respondents. This high level of women in student organizations is consistent with previous research which has found, for example, that $40 \%$ of participants in Engineers without Borders

are women, twice the representation of women among engineering students nationwide. ${ }^{14}$

\section{Overall Satisfaction}

On the whole, the majority of the students said that they were either satisfied or very satisfied with their undergraduate education, with $36 \%$ responding "very satisfied" and 50\% responding "satisfied". These numbers were consistent across subgroups of respondents. We also asked students to describe the factors that would make their engineering education more satisfying, with the findings summarized in Table 6 . Respondents reported that they would like their education to include more of: internship and work experiences, discussion of real world applications, choice of courses, and opportunities to study abroad. These factors are the same across different subgroups of students. 
The desire for more real world applications and better connections between industry and universities was also mentioned in the open-ended responses on the survey. One student wrote, " $I$ would love to see more interaction between the classroom concepts and professional industry! It is very frustrating to learn all of these theoretical formulas and not have a way to apply it. Engineering is about problem solving and critical thinking, not theory and equations." A number of students expressed similar ideas. Others specifically commented that they would like to see more coverage of BIM, Revit, and other industry software packages in the university setting.

\section{Future Plans: Undergraduate Students}

The survey continued by asking students about future plans. As reported in Table 7, the majority of the students were planning to seek full-time employment after graduation, although women and minorities were slightly more likely to plan to pursue graduate and professional school immediately. We also asked students about their plans to pursue graduate education in civil engineering at some time in the future, with results shown in Figure 6. According to these responses, most students did have plans for graduate school, and the majority of students planned to stay in civil engineering.

Table 6. What factor(s) would have made your undergraduate experience more satisfying?

\begin{tabular}{|c|c|c|c|c|c|}
\hline Factor * & Men & Women & Whites & URM & Others \\
\hline $\begin{array}{l}\text { More discussion of real world } \\
\text { applications }\end{array}$ & $19 \%$ & $16 \%$ & $18 \%$ & $15 \%$ & $13 \%$ \\
\hline More choice of courses & $13 \%$ & $12 \%$ & $13 \%$ & $10 \%$ & $16 \%$ \\
\hline $\begin{array}{l}\text { Broader introduction to civil } \\
\text { engineering disciplines }\end{array}$ & $3 \%$ & $4 \%$ & $4 \%$ & $4 \%$ & $2 \%$ \\
\hline Less homework & $7 \%$ & $4 \%$ & $7 \%$ & $2 \%$ & $0 \%$ \\
\hline More leadership opportunities & $6 \%$ & $3 \%$ & $5 \%$ & $2 \%$ & $7 \%$ \\
\hline $\begin{array}{l}\text { More opportunities to work with } \\
\text { other students on assignments }\end{array}$ & $5 \%$ & $5 \%$ & $4 \%$ & $6 \%$ & $7 \%$ \\
\hline More interaction with faculty & $9 \%$ & $10 \%$ & $10 \%$ & $11 \%$ & $9 \%$ \\
\hline $\begin{array}{l}\text { More interaction with people who } \\
\text { have different backgrounds from } \\
\text { me }\end{array}$ & $3 \%$ & $5 \%$ & $4 \%$ & $7 \%$ & $7 \%$ \\
\hline More research opportunities & $6 \%$ & $8 \%$ & $6 \%$ & $11 \%$ & $13 \%$ \\
\hline $\begin{array}{l}\text { More internship and/or applied or } \\
\text { work experiences }\end{array}$ & $21 \%$ & $18 \%$ & $18 \%$ & $23 \%$ & $18 \%$ \\
\hline $\begin{array}{l}\text { More opportunities to study } \\
\text { abroad }\end{array}$ & $7 \%$ & $13 \%$ & $11 \%$ & $10 \%$ & $9 \%$ \\
\hline Not applicable/not sure etc. & $2 \%$ & $0 \%$ & $2 \%$ & $0 \%$ & $0 \%$ \\
\hline
\end{tabular}

Table 7. Respondents' primary plan after graduation.

\begin{tabular}{cccccc} 
Planned post-graduation activity & Men & Women & White & URM & Others \\
\hline Paid employment, full-time & $71 \%$ & $67 \%$ & $71 \%$ & $60 \%$ & $69 \%$ \\
Paid employment, part-time & $0 \%$ & $1 \%$ & $0 \%$ & $4 \%$ & $0 \%$ \\
Graduate or professional school & $19 \%$ & $21 \%$ & $18 \%$ & $28 \%$ & $25 \%$ \\
Military service & $4 \%$ & $1 \%$ & $2 \%$ & $4 \%$ & $0 \%$ \\
Starting or raising a family & $0 \%$ & $0 \%$ & $0 \%$ & $0 \%$ & $0 \%$ \\
Travel & $1 \%$ & $4 \%$ & $2 \%$ & $4 \%$ & $0 \%$ \\
Undecided & $5 \%$ & $6 \%$ & $6 \%$ & $0 \%$ & $6 \%$
\end{tabular}


The survey finished by asking students about their certainty about their career choice. The responses collated in Figure 7 show that the majority of the students were either very certain or certain about their career choice at the time surveyed. However, the results also reveal that, among the survey cohort, men and underrepresented minorities were slightly more certain and excited about their career in civil engineering more than women and the other minority groups.

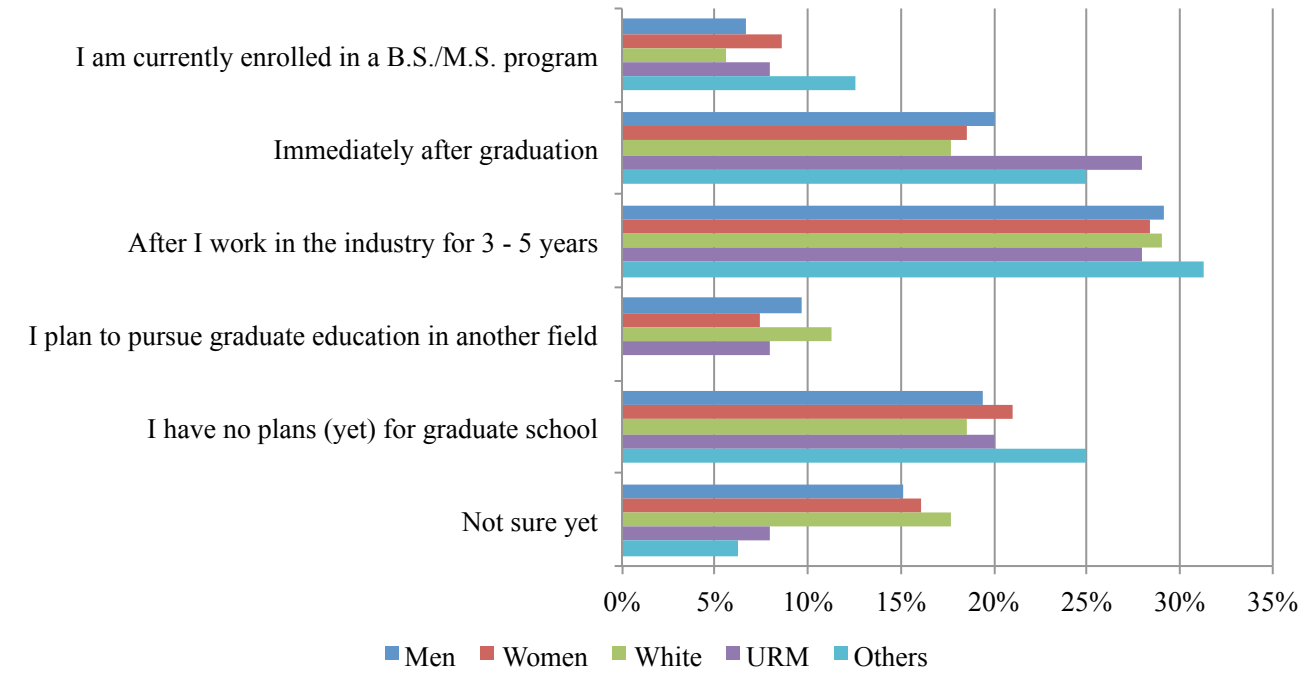

Figure 6. Undergraduate survey respondents' reported plans for graduate school.

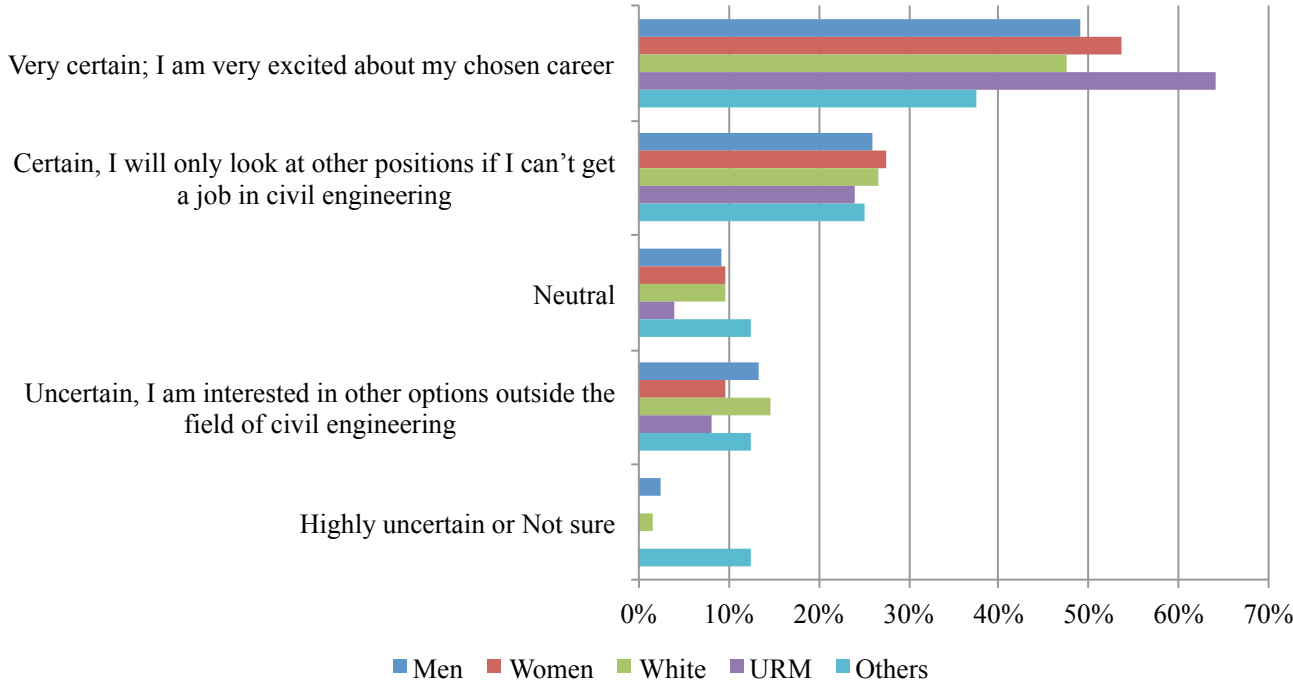

Figure 7. How certain are you about your career choice as a civil or architectural engineer?

\section{University experiences: Graduate students}

\section{Preparation}

For some context, the survey asked graduate students in what field they got their Bachelor's degree and, if in civil or architectural engineering, their discipline or emphasis of primary interest. The survey results show that $12 \%$ of the participants do not have a Bachelors degree in civil or architectural engineering. For the students who do, the most common disciplines in 
engineering that male students studied as an undergraduate were structures (40\%), construction management (12\%) and architectural design (12\%). For female students, the most common disciplines studied as an undergraduate were structures (48\%) and architectural design (18\%). Roughly $22 \%$ of the respondents had worked in the structural engineering industry for at least six months before attending graduate school. Another $14 \%$ worked in another engineering job. Forty-one percent of respondents said their undergraduate program prepared them very well for graduate school. These included $33 \%$ of male respondents and $58 \%$ of women respondents.

\section{$\underline{\text { Courses }}$}

Graduate students were asked about their experiences in graduate structural engineering coursework. As with the undergraduate respondents, the primary reasons given for liking a course were the professor, the professor's teaching style or method of presenting material, and the subject matter and material. The classroom environment, and assignments for the course, were given as reasons for disliking a class. There do not appear to be significant differences in the responses based on gender or race/ethnicity.

Next, the survey listed a variety of structural engineering courses that students may have taken as either an undergraduate or graduate student, and asked respondents to rate their experiences on a scale of 1 to 4 , where 1 indicates a "poor experience, decreased my overall confidence of succeeding in structural engineering" and 4 indicates a "great experience, increased my overall confidence of succeeding in engineering". The most popular courses (as reported in Table 8) among the survey respondents were structural analysis and earthquake engineering. Senior (capstone/integrated) design, finite element analysis and foundation engineering were given the lowest ratings. The finding that capstone design was unpopular was somewhat surprising, but the survey questions did not allow us to uncover reasons behind these responses.

Table 8. Respondents' ratings of experiences with the courses listed (Ratings: 1-4). The courses with the highest ratings are shown in italics. The courses with the lowest ratings are underlined.

\begin{tabular}{ccccccc} 
Course & $\begin{array}{c}\text { \% of Respondents } \\
\text { who have taken } \\
\text { this course }\end{array}$ & Men & Women & White & URM & Others \\
\hline $\begin{array}{c}\text { Statics } \\
\text { Mechanics of Materials }\end{array}$ & $95 \%$ & 3.5 & 3.4 & 3.6 & 4.0 & 3.1 \\
Structural Analysis & $100 \%$ & 3.3 & 3.4 & 3.2 & 3.4 & 3.4 \\
Steel Design & $97 \%$ & 3.8 & 3.6 & 3.7 & 3.7 & 3.7 \\
Reinforced Concrete Design & $90 \%$ & 3.3 & 3.5 & 3.5 & 3.2 & 3.1 \\
$\quad$ Senior Design & $63 \%$ & 3.4 & 3.5 & 3.6 & 3.4 & 3.1 \\
Structural Dynamics & $74 \%$ & $\underline{2.9}$ & $\underline{3.0}$ & $\underline{3.0}$ & $\underline{2.8}$ & $\underline{2.9}$ \\
Finite Element Analysis & $57 \%$ & $\underline{3.0}$ & $\underline{3.0}$ & $\underline{3.9}$ & $\underline{3.4}$ & $\underline{3.0}$ \\
Matrix Structural Analysis & $79 \%$ & 3.4 & 3.3 & 3.4 & 3.6 & 3.3 \\
Life-Cycle Engineering or & $40 \%$ & 3.5 & 3.3 & 3.8 & 2.7 & 3.1 \\
Structural Reliability & $31 \%$ & 3.2 & 3.3 & 3.4 & 4.0 & 2.8 \\
Bridge Engineering & $64 \%$ & $\underline{2.9}$ & $\underline{3.3}$ & $\underline{3.1}$ & $\underline{3.0}$ & $\underline{3.1}$ \\
Foundation Engineering & $41 \%$ & 3.5 & 3.9 & 3.8 & 4.0 & 3.2
\end{tabular}

As with the undergraduate survey, the survey asked participants to identify those aspects of their engineering program that most helped them to succeed as a graduate student. As shown in Figure 8 , the graduate students responded that doing homework and assignments was the most critical 
of the listed factors to their success. Among the secondary factors, the list is quite different among different groups of respondents. Women identified "engagement with professors and teaching assistants" and "collaboration with other students" as the next level of important factors. However, male graduate students identified the second most important factor as lecture/activities in class. Underrepresented minorities also seemed to rank collaboration with other students higher than some of the other groups of respondents. In summary, women, and to a lesser extent, minorities seemed to place a higher emphasis on the interactions with professors and other students, compared to white men. Compared to the undergraduate respondents (Figure 2), graduate students seem to place slightly more emphasis on homework assignments and textbooks, and less on collaboration with other students, and lectures/activities in class.

As with the undergraduate survey, we asked graduate students to rate their development of technical and non-technical skills during graduate school on a scale from 1 to 5 according to how much they think they have improved these skills during their engineering education. As summarized in Table 9, the graduate students rated their skill improvements the highest in the areas of critical thinking, information technology (programming, computer skills, etc.), and engineering design and applications. These are some of the same primary areas of skill improvement identified by the undergraduates (Table 5). Among the graduate students, women reported higher levels of improvement than men on all skills except for leadership and ethics.

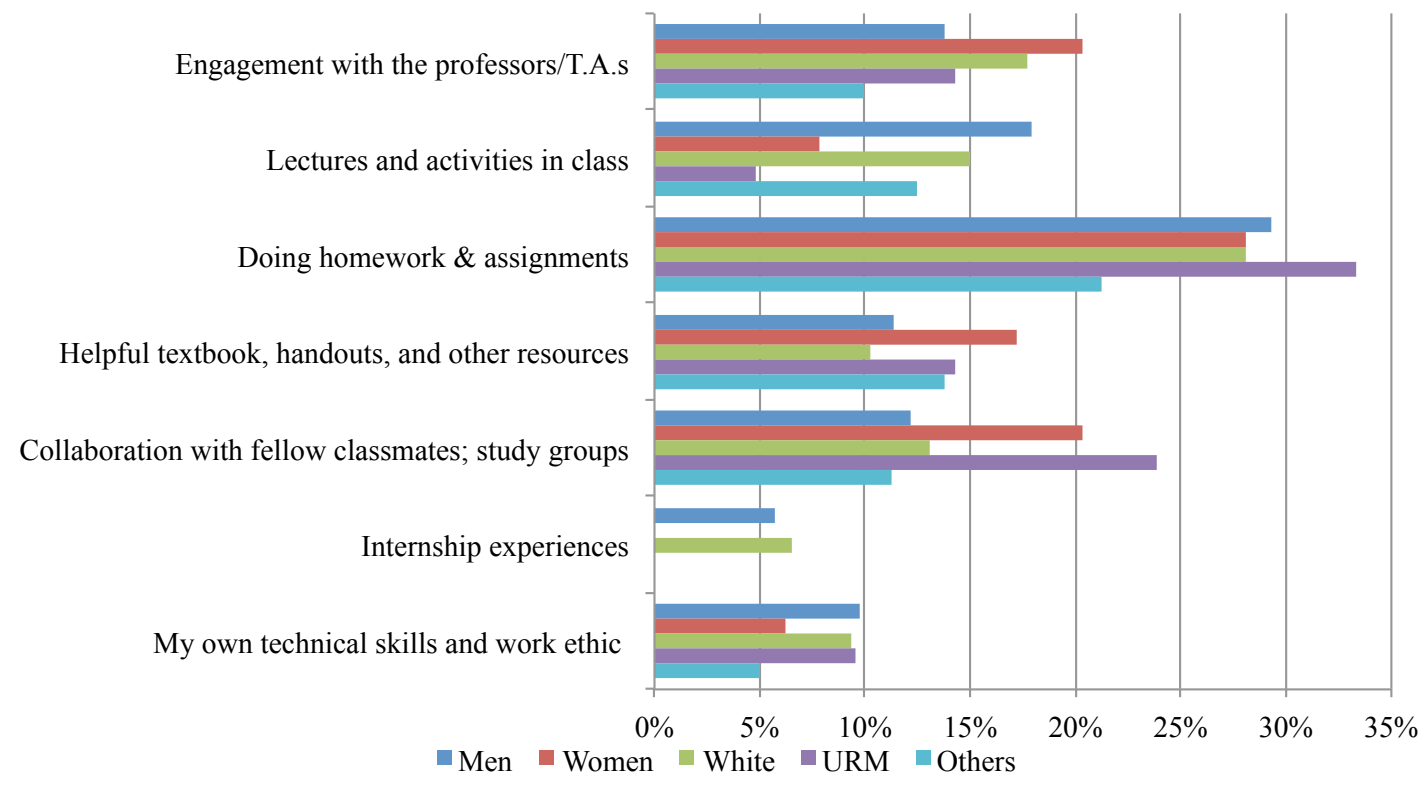

Figure 8. Which of the following has helped you succeed in your engineering courses? Respondents could select up to three choices.

Table 9. Respondents' ratings of skills developed during graduate education.

\begin{tabular}{cccccc} 
Skills & Men & Women & White & URM & Others \\
\hline Written Communication & 3.0 & 3.8 & 3.3 & 3.7 & 3.1 \\
Oral Communication & 3.2 & 3.4 & 3.6 & 3.0 & 2.9 \\
Critical Thinking & 3.8 & 4.3 & 4.0 & 3.9 & 3.9 \\
Leadership & 3.3 & 3.2 & 3.4 & 2.9 & 3.2 \\
Ethics & 3.3 & 3.0 & 3.2 & 3.0 & 3.3 \\
Mathematics & 3.5 & 3.8 & 3.5 & 3.9 & 3.6
\end{tabular}




$\begin{array}{cccccc}\text { Engineering design and applications } & 3.8 & 4.0 & 3.9 & 3.7 & 3.9 \\ \quad \text { Information technology, } & 3.6 & 4.2 & 3.7 & 4.1 & 3.9 \\ \text { programming \& computer skills } & & & & \end{array}$

Graduate students were asked the same questions about difficulty of coursework and the confidence they have in their technical skills as the undergraduate students. There do not seem to be much differences between the responses of male and female graduate students, with most students responding that the difficulty has been about right, or that some have been easy and some courses have been hard. Underrepresented minority students were more likely to say that courses were difficult, but recall that the sample size for this group was very small. Compared to undergraduate responses, graduate students were less likely to say that classes were either particularly easy or particularly hard. When asked about the confidence with their technical skills, the majority of the students either said that they have been very confident throughout, or that they were not very confident at the beginning, but are becoming more and more confident. Nevertheless, the differences observed been male and female respondents in the undergraduate survey results persists here, and white men in general indicated higher levels of confidence than women and minority students.

\section{Mentoring}

Seventy-eight percent of the graduate respondents said they have a mentor who strongly influenced their education and career choices. Unlike the undergraduate students, the graduate students most often reported that their mentor is a teacher or professor, and substantially fewer pointed to a family member/relative as an influential mentor. A number of respondents also identified employers or supervisors as important mentors.

\section{$\underline{\text { Involvement in Engineering Professional and Other Organizations }}$}

Almost all of the graduate students (85\%) documented some kind of participation in engineering societies as either an undergraduate or graduate student. The most commonly mentioned societies were ASCE, Chi Epsilon, the Earthquake Engineering Research Institute, and the Society of Women Engineers. As with the undergraduates, women were more likely to report active and leadership level involvement than other subgroups of respondents.

\section{$\underline{\text { Research, Internship and Work Experiences }}$}

We also asked graduate students about research, internship and work experience. Sixty-seven percent of the graduate students said that they had participated in independent study or research activities during either their undergraduate $(23 \%$ of those who had done research or independent studies) or graduate studies $(26 \%)$ or both (51\%). Among the survey respondents, women $(79 \%$ had participated in independent study or research) and underrepresented minorities $(86 \%)$ reported higher levels of participation, but due to the relatively small sample size, more research would be needed to confirm this finding. In addition, the results show that the majority of the students have participated in internships, with $54 \%$ of students responding they had interned in a structural engineering office, $28 \%$ interned in a civil engineering office, and $15 \%$ interned in a non-engineering office. 


\section{Overall Satisfaction}

The survey then asked students about their level of satisfaction with their graduate education. Seventy-eight percent of graduate students responded that they were either satisfied (40\%) or very satisfied (38\%) with their graduate education in structural engineering. These responses are very similar to those from undergraduates. We also asked students to describe the factors that would make their engineering education more satisfying, with the responses provided in Table 10. Graduate students identified the following factors as being important: (1) more choice of courses, (2) more internship and/or applied work experiences, (3) more discussion of real world applications, and (4) more interaction with faculty. The first three factors align closely with the responses provided by the undergraduate respondents (Table 6). Ninety percent of the graduate student respondents said they would recommend that a freshman pursue a degree/career in structural engineering.

Table 10. What factor(s) would have made your graduate engineering education more satisfying?

\begin{tabular}{|c|c|c|c|c|c|}
\hline Factor * & Men & Women & Whites & URM & Others \\
\hline \multicolumn{6}{|l|}{ More discussion of real world } \\
\hline applications & $14 \%$ & $11 \%$ & $16 \%$ & $16 \%$ & $5 \%$ \\
\hline More choice of courses & $16 \%$ & $24 \%$ & $14 \%$ & $32 \%$ & $16 \%$ \\
\hline \multicolumn{6}{|l|}{ Broader introduction to civil engineering } \\
\hline disciplines & $4 \%$ & $7 \%$ & $0 \%$ & $5 \%$ & $9 \%$ \\
\hline Less homework & $3 \%$ & $4 \%$ & $5 \%$ & $5 \%$ & $1 \%$ \\
\hline More leadership opportunities & $5 \%$ & $4 \%$ & $5 \%$ & $5 \%$ & $4 \%$ \\
\hline \multicolumn{6}{|l|}{ More opportunities to work with other } \\
\hline students on assignments & $6 \%$ & $7 \%$ & $7 \%$ & $11 \%$ & $3 \%$ \\
\hline More interaction with faculty & $10 \%$ & $7 \%$ & $6 \%$ & $11 \%$ & $11 \%$ \\
\hline \multicolumn{6}{|l|}{ More interaction with people who have } \\
\hline different backgrounds from me & $8 \%$ & $2 \%$ & $10 \%$ & $0 \%$ & $3 \%$ \\
\hline More research opportunities & $8 \%$ & $4 \%$ & $7 \%$ & $0 \%$ & $7 \%$ \\
\hline \multicolumn{6}{|l|}{ More internship and/or applied or work } \\
\hline experiences & $14 \%$ & $17 \%$ & $16 \%$ & $16 \%$ & $11 \%$ \\
\hline More opportunities to study abroad & $8 \%$ & $9 \%$ & $11 \%$ & $0 \%$ & $5 \%$ \\
\hline Not applicable/not sure etc. & $14 \%$ & $11 \%$ & $16 \%$ & $16 \%$ & $5 \%$ \\
\hline
\end{tabular}

*In this question, respondents were asked to identify the three most important factors from the list provided. The most popular answers are italicized.

\section{Future Plans: Graduate Students}

Responses to questions about plans for plans for life after graduate school are compiled in Table 11. Some of the respondents reported being undecided, but majority of the students were seeking full-time employment after graduation; others were planning to pursue further higher education.

As with the undergraduate students, the survey asked graduate students about their certainty about their career choice. Responses (Figure 9) revealed that most respondents were "very certain" or "certain" about their chosen career. Graduate students were somewhat more certain than undergraduates about their career with only $17 \%$ giving a neutral or negative answer ("neutral", "uncertain", "highly uncertain", or "don't know"), compared to $25 \%$ of undergraduate respondents. However, women were more likely than men to express uncertainty or neutral feelings about their career ( $26 \%$ of women compared to $13 \%$ of men). 


\section{Perspectives on diversity in civil \& structural engineering}

To explore how diversity and opportunities in civil/structural engineering profession are perceived, both undergraduate and graduate students were asked questions about whether there are equal opportunities of success for all in civil/structural engineering or if some groups have fewer opportunities to succeed. The responses are plotted in Figure 10. Women and minority survey participants were less likely to say they "believe that there are equal opportunities for everyone". Indeed, $46 \%$ of female student respondents and $65 \%$ of non-white student respondents responded that they believe there are fewer opportunities in civil/structural engineering for women, minorities or both. These response rates for these questions are in contrast to $28 \%$ of men and $24 \%$ of white respondents. A similar survey conducted of structural engineering professionals ${ }^{3}$ found that among professional respondents, $55 \%$ of women and $45 \%$ of non-white survey participants said there are fewer opportunities in structural engineering for women or minorities. This seems to suggest a more negative view from female professionals than female students on this issue, but the opposite trend among minority respondents. Students who believe that there are fewer opportunities for women and minorities primarily attribute this to a lack of women/minority role models in industry (38\%), inequalities that exist in the profession (32\%), family commitments $(15 \%)$, and differences in how people think and approach problems $(15 \%)$. The reasons given for believing there are fewer opportunities were generally similar across genders and race/ethnic background, and to the responses from structural engineering professionals. ${ }^{3}$

Table 11. Graduate school respondents' primary plan after graduation.

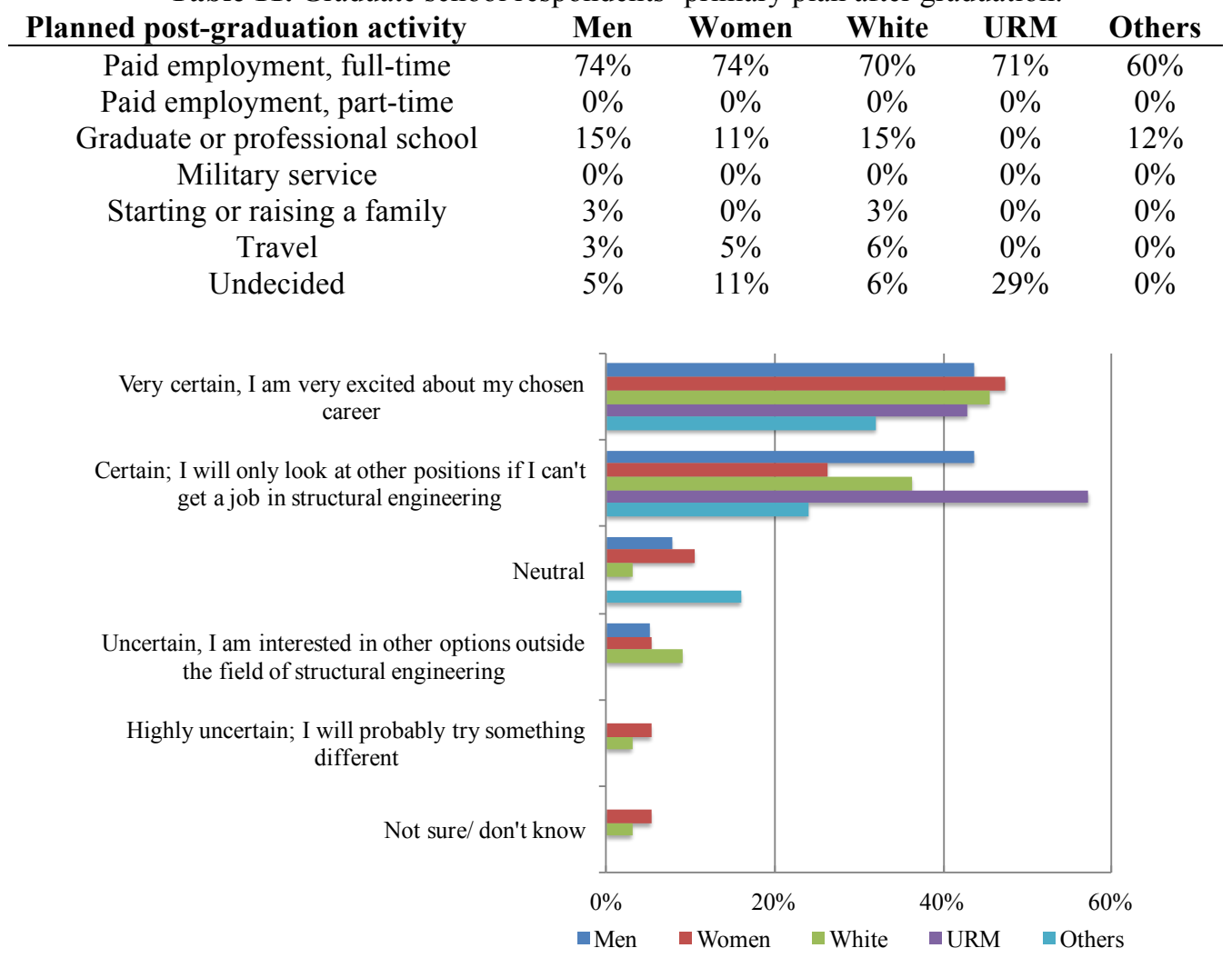

Figure 9. How certain are you about your career choice as a civil or architectural engineer? 


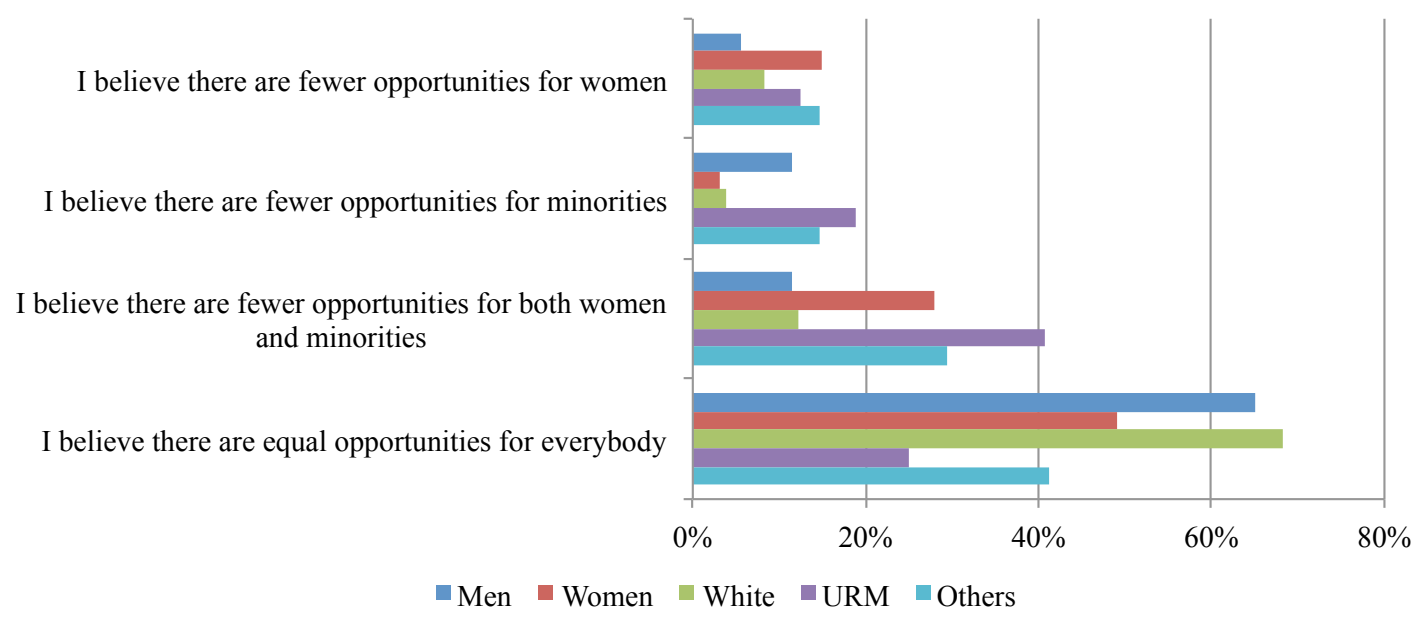

Figure 10. Do you believe some groups of people have fewer opportunities to succeed in structural engineering careers?

\section{Conclusions}

This paper describes responses to a survey taken by over 200 undergraduate and graduate students in civil and structural engineering. Respondents were 55\% male and $45 \%$ female, and $70 \%$ white. Analyses of survey responses show that students of all backgrounds choose civil engineering, and the subdiscipline of structural engineering, for the same reasons. However, comparing the responses of different groups based on gender and race/ethnicity, there are significant differences in university experiences between groups of respondents. These difference are manifested in terms of students' self-reported confidence, the development of social networks and mentoring relationships, and their interests in different aspects of the required course work, which impact career goals and expectations.

Examining especially the experiences of women and minorities, the study finds that students of different backgrounds enjoy similar aspects of classes, but women and minorities seem to place somewhat more emphasis on collaboration with their classmates and their relationship with their professors. In addition, white male students expressed more confidence and rated their skills higher (relative to their classmates), despite having the same distribution of GPAs as the other subgroups of respondents. These results illustrate how important the development of personal and professional relationships with practicing engineers is for recruiting and retaining all students, but especially women and minorities. Programs that help students get to know professionals and the workplace may help. It is also important for educators and industry to recognize that men and women express confidence differently, and that this may not be a true representation of ability. Active learning and other activities in the classroom that enhance collaboration and connections between people may also help motivate diverse students.

The study also finds that almost all the students surveyed reported some involvement in professional societies and organizations. ASCE's steel bridge and concrete canoe competitions were reported to be very popular. In addition, women and minority students were more likely to report very active or leadership-level involvement. This relatively high level of student engagement in engineering societies represents a significant opportunity to strengthen 
connections between universities and industry. Connections between industry and campus chapters of professional organizations offers opportunities to recruit students with leadership experience, including women and minorities.

On the whole, this study finds that students have very little exposure to engineering professionals and real world projects during their time at university. Only $26 \%$ of the undergraduate students had participated in research or independent study. Fifty-five percent had completed internships, but many of these were not in the student's chosen field of study. Most respondents ranked more internship opportunities and more discussion of real world applications very highly on their list of things they wish had been different about their education. Despite this, senior design class, which is often organized around a real world project, was not a very popular course and earned some of the lowest ratings of all the courses. Unfortunately, the survey did not collect data on the specific characteristics of senior design classes at different universities or what aspects of this course seem to make it unpopular. These findings support the general observation that students are seeking more real world experience earlier in their college career. Efforts should be made to facilitate site visits and visits to engineering firms, as well as greater number of internships.

Given the large number of respondents who cited "desire to make a difference" as one of the factors contributing to their interest in civil and/or structural engineering, more opportunities to engage with engineering in the community may also be important.

In general, the results of this survey substantiate, for civil and structural engineering students, the findings of other more general studies of women and minorities' experiences in science and technology related fields. For example, previous research has demonstrated that women may be more attracted to aspects of teamwork and a sense of community ${ }^{15}$. Activities outside of the classroom, such as involvement in engineering societies, have also been shown be particularly influence for women ${ }^{16}$. Therefore, this study serves to demonstrate the unexceptional nature of the challenge of diversity in civil and structural engineering. Classroom and extracurricular techniques that have proved successful at retaining a diverse student body in other STEM disciplines, or engineering more generally, are likely appropriate in these subdisciplines as well.

\section{Acknowledgments}

This survey was supported in part by the ASCE Structural Engineering Institute through a grant to the Young Professionals Committee. This study was also supported by a University of Colorado IMPART (Implementation of Multicultural Perspectives and Approaches in Research and Teaching) Faculty Fellowship grant. The contributions of other members of the ASCE/SEI Young Professionals Committee, particularly Emily Guglielmo and Judith Mitrani-Reiser, are gratefully acknowledged.

\section{Bibliography}

\footnotetext{
${ }^{1}$ National Academy of Sciences (NAS) (2006). Beyond Bias and Barriers: Fulfilling the Potential of Women in Academic Science and Engineering. Washington, DC: National Academies Press.
} 
${ }^{2}$ National Science Foundation (NSF) Division of Science Resources Statistics (2007). Women, Minorities, and Persons with Disabilities in Science and Engineering. NSF: Arlington, VA.

${ }^{3}$ Liel, Abbie B. and SEI Young Professionals Committee. "Diversity in the Structural Engineering Profession: Challenges and Opportunities", Structure Magazine, October, 2014.

${ }^{4}$ Valian, V (1998). Why So Slow? The Advancement of Women. MIT Press: Cambridge, MA.

${ }^{5}$ Schreuders, P.D., Mannon, S.E. and Rutherford, B. March 2009. "Pipeline or Personal Preference: Women in Engineering." European Journal of Engineering Education, 34(1), pg. 97-112.

${ }^{6}$ Marszalek, J., Linnemeyer, S. A., and Haque, T. (2009). “A Cox regression analysis of a women's mentoring program in engineering." J. Women Minor. Sci. Eng., 15(2), 143-165.

${ }^{7}$ Fouad, N. A., and Singh, R. (2011). Stemming the tide: Why women leave engineering, Univ. of WisconsinMilwaukee, Milwaukee, WI.

${ }^{8}$ Gill, J., Sharp, R., Mills, J., and Franzway, S. (2008). "I still wanna be an engineer! Women, education and the engineering profession." European Journal of Engineering Education, 33(4), 391-402.

${ }^{9}$ Roberts, P., and Ayre, M. (2002). "Did she jump or was she pushed? A study of women's retention in the engineering workforce." International Journal of Engineering Education, 18(4), 415-421.

${ }^{10}$ Seymour, E., and Hewitt, N. M. (1997). Talking about leaving, Westview, CO.

${ }^{11}$ Mcllwee, Judith S. and J. Gregg Robinson. 1992. Women in Engineering: Gender, Power and Workplace Culture. State University Press of New York: Albany.

${ }^{12}$ ASEE (2012), Engineering Colleges Database.

${ }^{13}$ Umbach, P. D. (2004), "Web surveys: Best practices." New Directions for Institutional Research, pp. 23-38.

${ }_{15}^{14}$ Engineers without Borders. Available at: www.ewb-usa.org

${ }^{15}$ Allendoerfer, C., et al. (2012). "Strategic pathways for success: The influence of outside community on academic engagement." Journal of Eng. Educ., 101(3), 512-538.

${ }^{16}$ Dean, D. J., and Fleckenstein, A. (2007). "Keys to success for women in science." Women and minorities in science, technology, engineering and mathematics: Upping the numbers, Edward Elgar, Northampton, MA, $28-44$. 